\title{
Incidence trends in high-grade primary brain tumors in males and females
}

\author{
JONAS NILSSON $^{1-3}$, GEORG HOLGERSSON ${ }^{1,4}$, TOBIAS CARLSSON ${ }^{4}$, \\ ROGER HENRIKSSON ${ }^{2,5}$, STEFAN BERGSTRÖM ${ }^{1,4}$ and MICHAEL BERGQVIST ${ }^{1,2,4}$
}

${ }^{1}$ Centre for Research and Development, Uppsala University/Region Gävleborg, SE-801 87 Gävle; ${ }^{2}$ Department of Radiation Sciences and Oncology, Umeå University Hospital, SE-901 87 Umeå; Departments of ${ }^{3}$ Radiology and ${ }^{4}$ Oncology, Gävle Hospital, SE-801 88 Gävle; ${ }^{5}$ Regional Cancer Center Stockholm-Gotland, Västgötagatan 2, SE-102 39 Stockholm, Sweden

Received July 2, 2016; Accepted December 6, 2016

DOI: $10.3892 / \mathrm{ol} .2017 .5770$

\begin{abstract}
The focus of the present review is to investigate whether there is a variation in the incidence rates between male and female patients with high-grade primary brain tumors and if there are altered incidence rates associated with the time at which they were diagnosed. Previous studies identified in internationally peer-reviewed journals were identified using a systematic search of the PubMed database. Due to the difficulties in data interpretation, studies that exclusively included patient data classified prior to the 2nd edition of the World Health Organization histological classification system of brain tumors were excluded. The overall incidence rates and incidence trends of male and female patients were analyzed separately. The mean age-adjusted overall incidence rate in the male population was 1.27 per 100,000 compared with 0.89 per 100,000 in the female population. The variance between the two genders differed and a Wilcoxon rank-sum test indicated that there was no significant difference in the incidence rate of high-grade primary brain tumors between males and females $(\mathrm{P}=0.3658)$. Furthermore, there was no significant difference in incidence rate trend between 1996-2004 and 2005-2010 for male or female populations $(\mathrm{P}=0.101$ and $\mathrm{P}=0.472$, respectively). The results from the present systematic review did not demonstrate a significant difference in incidence rate between the two genders. Therefore, the results from the current study are considered to be preliminary and further studies are required to elucidate this issue.
\end{abstract}

\section{Introduction}

Primary brain tumors are defined as abnormal tissue within the brain, meninges, cranial nerves, skull, pituitary gland and pineal gland (1). The 2007 World Health Organization (WHO) classification system of brain tumors is an established system

Correspondence to: Dr Jonas Nilsson, Department of Oncology, Gävle Hospital, 1 Lasarettvägen, Gävleborg, SE-801 88 Gävle, Sweden E-mail: jonas.nilsson@ regiongavleborg.se

Key words: incidence trends, high-grade brain tumors, gender that divides brain tumor cases into distinct groups based on their histopathological characteristics (2). The system uses a four-point scale in which grade I and II describe tumors with low proliferation rates and grade II tumors may present characteristics of infiltration (2). Grade III and IV describe malignant tumors presenting with aggressive behavior and, typically, a poorer prognosis (2). This classification system is used in the clinical setting to decide on the type of therapy that may be effective; including surgical resection only, adjuvant radiotherapy, chemotherapy or a combination (2).

The Swedish brain study consortium previously published a study concerning the treatment and the survival rates of patients with a brain tumor between 1999 and 2012 (3). In addition, a number of previous studies have investigated the incidence rate and the trends of incidence rates in high-grade primary brain tumors (4-6). These previous studies also compared the incidence rates of high-grade brain tumors between the two genders (4-6). Previous studies have used data from national registries, including the National Program of Cancer Registries, and Surveillance, Epidemiology and End Results Program (SEER) $(7,8)$, and to the best of our knowledge, there has not been a worldwide international comparison to determine the potential variation in incidence rate between male and female patients with a high-grade primary brain tumor. Any significant differences in incidence rate between the two genders may lead to novel future studies. The current study also focuses on the incidence rate of male and female adult patients with a high-grade primary brain tumor during two time periods.

\section{Materials and methods}

Electronic database searches and article selection strategy. Articles from internationally peer-reviewed journals were identified using a systematic search of PubMed (www.ncbi.nlm.nih. gov/pubmed). The medical subject headings (MeSH) terms used for literature searches were 'brain cancer incidence time trends'. Due to the challenges of interpreting data, previous studies that exclusively included patient data prior to the 2 nd edition of WHO histological classification system of brain tumors were excluded (9). Previous studies that were not written in the English language, studies that did not include data for high-grade 
(WHO III-IV) primary brain tumors and previous reviews and studies that excluded adult subjects were also excluded.

Data extraction. For each identified study the following data was extracted: Histology, data source, study period (years), demography, number of subjects that were included, age interval and average age-adjusted annual incidence rate separated by gender.

Statistical analysis. Data presentation includes a description of the dataset disseminated with the primary variables covered, the classifications and breakdowns used, the reference area, a summary information on the time period covered and the base period used. The overall analysis was performed using STATA software (version 13; StataCorp LP, College Station, TX, USA). As determined using a Shapiro-Wilk W test, the data demonstrated a non-normal distribution $(\mathrm{P}<0.0001)$. Therefore, the Wilcoxon-Mann-Whitney test was performed to identify significant differences between the incidence rates of male and female patients with high-grade primary brain tumors. Trend analysis was performed using the 'nptrend' test (STATA; StataCorp LP) for trends across ordered groups. The incidence rates within each gender during the time periods of 1995-2004 and 2005-2010 were also compared. The incidence trends were also analyzed for male and female patients separately. The time periods were selected due to the small number of previous studies that performed analysis of incidence rates prior to 2005. $\mathrm{P}<0.05$ was considered to indicate a statistically significant difference.

\section{Results}

Summary of the literature. A total of 225 studies were identified during the literature search and 20 studies were excluded as they were not written in English, were review articles, were comments on other studies or were not available online (Fig. 1). Of the remaining 205 studies, 194 studies were excluded due to the following criteria: 49 studies that did not include data on primary brain tumors; 55 studies with no information on the incidence rate; 23 studies excluded adult patients; 43 studies exclusively included patient data prior to $1993 ; 5$ studies exclusively included data on non-western populations; 4 were laboratory studies; 15 studies did not exclusively include data on high-grade brain tumors. The remaining 11 studies included information on high-grade tumors and are reviewed in the current study. However, all studies that included incidence rate data on ependymal tumors did not separate anaplastic ependymoma from other ependymal tumor types and, therefore, these results were not included in the analysis (Table I) $(4,5,10,11)$. Similarly, as the studies that included choroid plexus tumors did not differentiate choroid plexus carcinoma from lower grade tumor types, these results were also not included $(4,5)$. Oligoastrocytic tumors, neuronal and mixed neuronal-glial tumors, pineal tumors and two studies that including meningioma also did not differentiate the low-grade tumors from the high-grade tumors and consequently these results were excluded from the analysis $(4,5,10)$.

Results of the incidence rate analysis. The mean age-adjusted overall incidence rate in male patients with high-grade primary brain tumors was 1.27 per 100,000 compared with 0.89 per
100,000 in female patients. There was no significant difference in the incidence rates identified between male and female patients, as evaluated using a Wilcoxon-Mann-Whitney test $(\mathrm{P}=0.37)$. There were no significant differences identified in the incidence rate trends between 1996-2004 and 2005-2010 in male $(\mathrm{P}=0.10)$ or female patients $(\mathrm{P}=0.47)$ with high-grade primary brain tumors.

\section{Incidence rates and gender differences}

Astrocytic tumors. A total of eight studies included analysis of astrocytic tumors but only six studies reported age-adjusted incidence rates for these tumors (Table II). Of these six studies, one study exclusively analyzed incidence rates from African-American populations, four studies reported data based on United States registries and one study investigated data exclusively from Croatia $(4,5,10-13)$. As indicated in Table III, the studies with patients diagnosed with anaplastic astrocytomas that were identified with the International Classification of Disease for Oncology (ICD-O) (14) morphology codes 9401 and 9411, had an age-adjusted incidence rate that ranged from 0.2-0.6 per 100,000 for male patients and 0.1-0.4 per 100,000 for female patients with high-grade brain tumors between 1973 and 2010. In studies with patients diagnosed with glioblastomas (ICD-O codes 9040-9042), the age-adjusted incidence rate ranged from 2.3-5.54 per 100,000 for male patients and 1.5-4.6 per 100,000 for female patients with high-grade brain tumors between 1973 and 2010.

Oligodendroglial tumors. Five studies reported data on patients with oligodendroglial tumors (ICD-O codes 9451 and 9460); however, only three articles analyzed the data for age-adjusted incidence rates. Two studies used data exclusively from the United States and one study investigated data from a Croatian population. The incidence rates from these previous studies ranged from 0.13-0.5 per 100,000 for male patients and 0.09-0.1 per 100,000 for female patients between 1996 and 2010 (Table II) $(4,5,11)$.

Central nervous system embryonal tumors. A total of four studies reported data on embryonal tumors. These studies analyzed data from United States registers. The age-adjusted incidence rates ranged from $0.09-0.3$ per 100,000 for male patients and 0.07-0.22 per 100,000 for female patients between 1973 and 2010 (Table II) $(4,5,15,16)$.

Meningeal tumors. Gabriel et al (12) investigated the incidence rates of patients with malignant meningioma in the African-American population from the United States between 1973 and 2008. The male incidence rate was 0.20 per 100,000 compared with 0.30 per 100,000 for female patients during this time period. During the analyses of the time period between 1998 and 2008, the male incidence rate was 0.19 per 100.000 compared with the female incidence rate of 0.34 per 100.000 . There was no male to female incidence rate ratio reported (Table II) (12).

\section{Discussion}

In the present study, the mean age-adjusted overall incidence rate of high-grade brain tumors was identified to be 1.27 per 
Table I. Exclusions due to non-differentiation between low grade and high-grade tumors.

\begin{tabular}{|c|c|c|c|}
\hline Author, year & Histology & ICD-O code & Refs \\
\hline Ostrom et al, 2013 & Oligoastrocytic tumors & 9382 & (4) \\
\hline Dolecek et al, 2009 & Oligoastrocytic tumors & 9382 & $(5)$ \\
\hline Gittleman et al, 2015 & Oligoastrocytic tumors & 9382 & $(10)$ \\
\hline Ostrom et al, 2013 & Pineal tumors & $9360,9361,9362$ & (4) \\
\hline Dolecek et al, 2009 & Pineal tumors & $9360,9361,9362$ & $(5)$ \\
\hline Ostrom et al, 2013 & Ependymal tumors & $9383,9391,9392,9393,9394$ & (4) \\
\hline Dolecek et al, 2009 & Ependymal tumors & $9383,9391,9392,9393,9394$ & $(5)$ \\
\hline Gittleman et al, 2015 & Ependymal tumors & $N A$ & $(10)$ \\
\hline Dobec-Meić et al, 2006 & Ependymal tumors & $N A$ & $(11)$ \\
\hline Ostrom et al, 2013 & $\begin{array}{l}\text { Neuronal and mixed } \\
\text { neuronal-glial tumors }\end{array}$ & $\begin{array}{l}8680,8681,8690,8693,9412,9413,9442, \\
9492,9493,9505,9506,9522,9523\end{array}$ & (4) \\
\hline Dolecek et al, 2009 & $\begin{array}{l}\text { Neuronal and mixed } \\
\text { neuronal-glial tumors }\end{array}$ & $\begin{array}{l}8680,8681,8690,8693,9412,9413 \\
9442,9492,9493,9505,9506,9522,9524\end{array}$ & $(5)$ \\
\hline Ostrom et al, 2013 & Choroid plexus tumors & 9390 & (4) \\
\hline Dolecek et al, 2009 & Choroid plexus tumors & 9390 & $(5)$ \\
\hline Ostrom et al, 2013 & Meningioma & $\begin{array}{l}9530,9531,9532,9533,9534,9537, \\
9538,9539\end{array}$ & (4) \\
\hline Dolecek et al, 2009 & Meningioma & $\begin{array}{l}9530,9531,9532,9533,9534,9537 \\
9538,9539\end{array}$ & $(5)$ \\
\hline
\end{tabular}

$N A$, information not available; ICD-O, international classification of diseases of oncology; Refs, reference number.

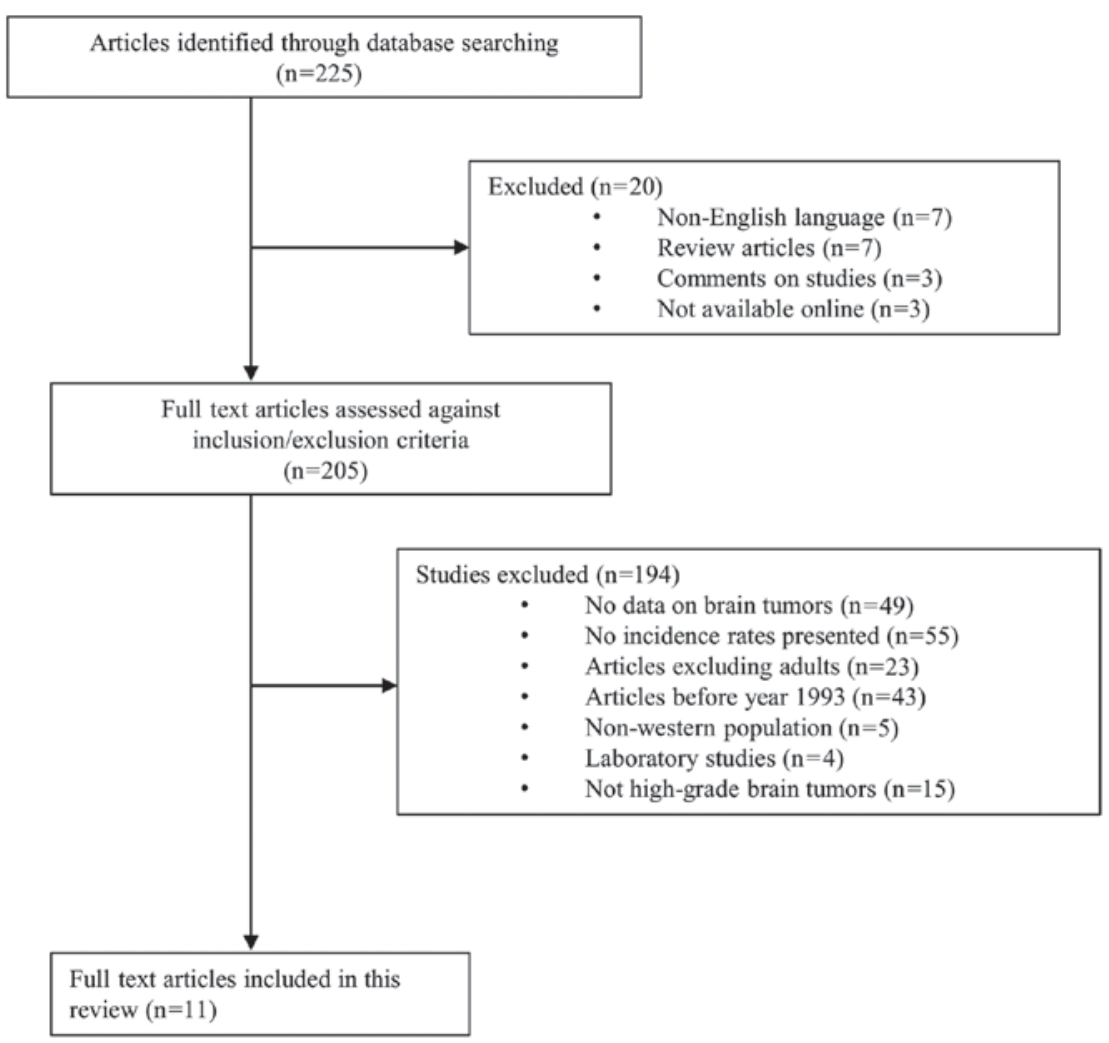

Figure 1. Article selection process. The flow diagram presents the previous studies that were identified and excluded in the literature search. $n=$ number of studies.

100,000 for male patients compared with 0.89 per 100,000 for female patients. Analysis with the Wilcoxon-Mann-Whitney test did not identify a significant difference in the incidence rate between male and female patients with high-grade brain tumors. Furthermore, there was no significant difference in the incidence rate trend between 1996-2004 and 2005-2010 


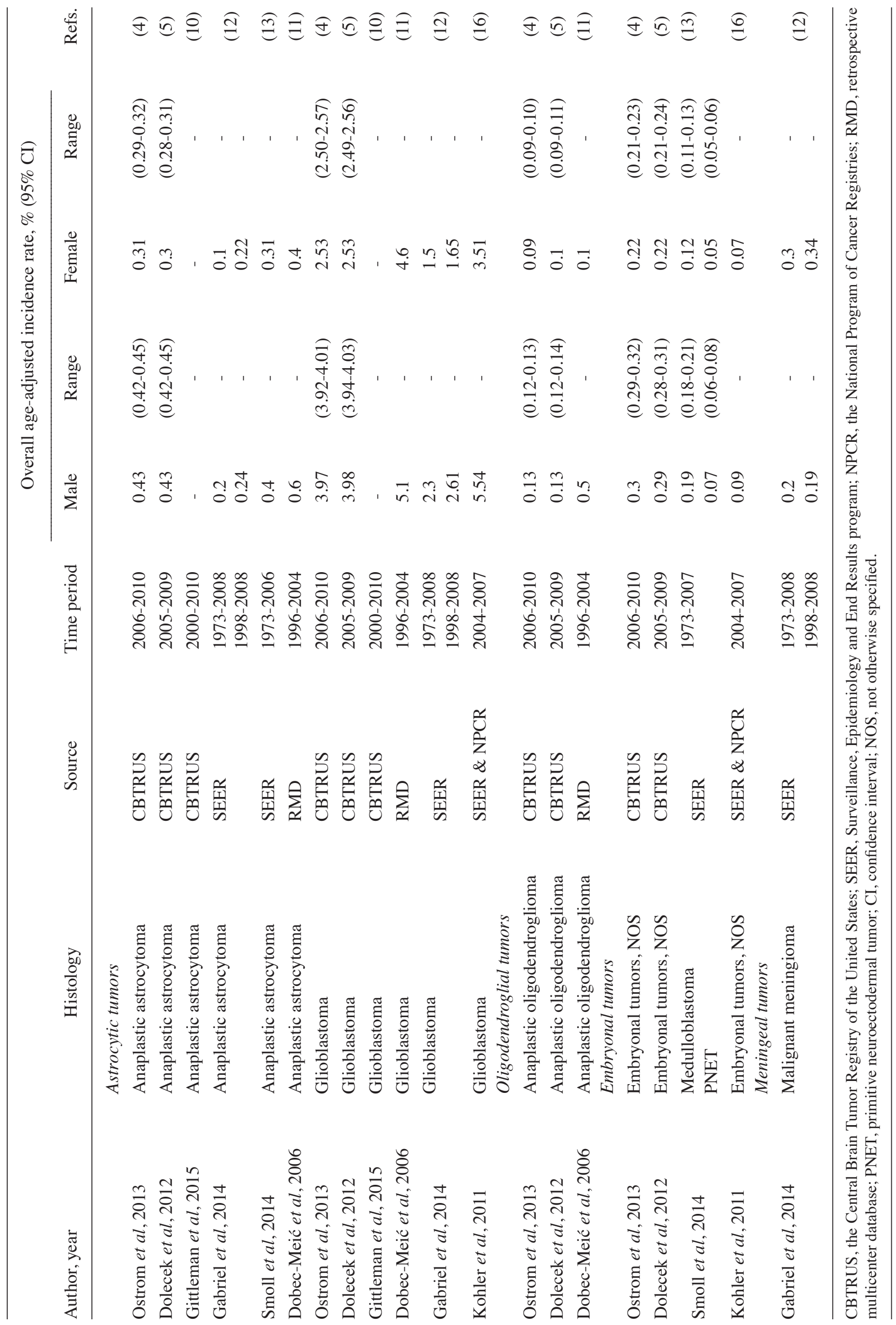


Table III. Studies included in the current review.

\begin{tabular}{|c|c|c|c|}
\hline Author, year & Article & Demography & Refs. \\
\hline Ostrom et al, 2013 & $\begin{array}{l}\text { CBTRUS statistical report: Primary } \\
\text { brain and central nervous system tumors } \\
\text { diagnosed in the United States in 2006-2010 }\end{array}$ & USA & (4) \\
\hline Dolecek et al, 2012 & $\begin{array}{l}\text { CBTRUS statistical report: Primary brain and } \\
\text { central nervous system tumors diagnosed in } \\
\text { the United States in 2005-2009 }\end{array}$ & USA & $(5)$ \\
\hline Gittleman et al, 2015 & $\begin{array}{l}\text { Trends in central nervous system tumor incidence } \\
\text { relative to other common cancers in adults, adolescents, } \\
\text { and children in the United States, } 2000 \text { to } 2010\end{array}$ & USA & $(10)$ \\
\hline Dobec-Meić et al, 2006 & $\begin{array}{l}\text { Intracranial tumors in adult population of the } \\
\text { Varazdin County (Croatia) 1996-2004: A population- } \\
\text { based retrospective incidence study }\end{array}$ & Croatia & $(11)$ \\
\hline Gabriel et al, 2014 & $\begin{array}{l}\text { Adult brain cancer in the U.S. black population: } \\
\text { A Surveillance, Epidemiology, and End Results (SEER) } \\
\text { analysis of incidence, survival, and trends }\end{array}$ & USA & $(12)$ \\
\hline Smoll et al, 2014 & Incidence and relative survival of anaplastic astrocytomas & USA & (13) \\
\hline Smoll et al, 2012 & $\begin{array}{l}\text { The incidence of medulloblastomas and primitive } \\
\text { neurectodermal tumours in adults and children }\end{array}$ & USA & $(15)$ \\
\hline Kohler et al, 2011 & $\begin{array}{l}\text { Annual report to the nation on the status of cancer, } \\
\text { 1975-2007, featuring tumors of the brain and other } \\
\text { nervous system }\end{array}$ & USA & $(16)$ \\
\hline
\end{tabular}

CBTRUS, the central brain tumor registry of the united states.

in male or female populations $(\mathrm{P}=0.10$ and $\mathrm{P}=0.47$, respectively).

The results from the current study present a compilation of available literature that was identified using a systematic search of PubMed and the MeSH terms 'brain cancer incidence time trends'. A total of 225 articles were identified during the literature search. There were 11 studies remaining following the application of the exclusion criteria and these studies were of varying quality. The majority of the studies were based on United States registry data. A European study was also included, but had limited data for 264 patients, including numerous types of intracranial tumors, therefore the incidence rate has reduced validity and it may be problematic to interpret the results (11). The European study also presented the number of patients in terms of incidence rate that was not age-adjusted and, subsequently, the results are not be able to be compared with the other studies reducing the validity of the findings (11). As the majority of the data was from United States registers, the analysis in the current review may represent the trends of incidence rate in the United States population and not a worldwide comparison of incidence rate for high-grade brain tumors. However, the data in the present review was evaluated to establish results with validity. Furthermore, the present review included all available studies according to the study criteria and the studies that have been excluded have been accounted for.

The two time periods, 1996-2004 and 2005-2010, were examined to identify the incidence rate trend in high-grade gliomas. The length of each time period is unequal due to the variation in the number of studies that were analyzed for the incidence rates. As there were more results examined in the later time period, the time periods were altered to equalize the quantity of data in each. This may require consideration when interpreting the results of the current study, as the earlier group may not be as representative due to the reduced number of patients that were included.

It is also important to consider that the histological definitions of several types of brain cancer have historically been varied, with revised histological classifications of tumors, and there has not been a review of the incidence rate of specific tumors in the SEER database, including anaplastic astrocytomas (13). This may affect the validity of the incidence rate data.

As there were a number of criteria for inclusion, there may be important data that is absent from the current review. Data identified from scientific conferences or data available from other electronic databases have not been included; therefore, relevant studies may have been excluded. Furthermore, the majority of the studies that were included were from populations from the United States and the average annual age-adjusted incidence rate in the present study may be considered to be based on the 2000 U.S. standard population. By contrast, Gabriel et al (12) did not indicate the standard population and Dobec-Meić et al (11) evaluated the 2001 Croatian census data. This implies that the variation in the incidence rates may be due to the differing calculations, rather than on the absolute incidence rate. Several previous studies that were reviewed used the same register data but for varied time-periods, which overlapped in certain cases $(4,5,10,12,13,15,16)$. Therefore, interpretation of this data may be problematic, as the results 
Table IV. Population standard by histological category.

\begin{tabular}{|c|c|c|c|c|}
\hline Author, year & Histology & ICD-O code & Population & Refs. \\
\hline & Astrocytic tumors & & & \\
\hline Ostrom et al, 2013 & Anaplastic astrocytoma & 9401 & $\begin{array}{l}2000 \text { U.S. Standard } \\
\text { Population }\end{array}$ & (4) \\
\hline Dolecek et al, 2012 & Anaplastic astrocytoma & 9401 & $\begin{array}{l}2000 \text { U.S. Standard } \\
\text { Population }\end{array}$ & $(5)$ \\
\hline Gittleman et al, 2015 & Anaplastic astrocytoma & 9401 & $\begin{array}{l}2000 \text { U.S. Standard } \\
\text { Population }\end{array}$ & $(10)$ \\
\hline Dobec-Meić et al, 2006 & Anaplastic astrocytoma & $N A$ & $\begin{array}{l}2001 \text { Census Data } \\
\text { (Croatia) }\end{array}$ & $(11)$ \\
\hline Gabriel et al, 2014 & Anaplastic astrocytoma & $N A$ & $N A$ & (12) \\
\hline Smoll et al, 2014 & Anaplastic astrocytoma & $N A$ & $\begin{array}{l}2000 \text { U.S. Standard } \\
\text { Population }\end{array}$ & $(12)$ \\
\hline Ostrom et al, 2013 & Glioblastoma & $9440-9442$ & $\begin{array}{l}2000 \text { U.S. Standard } \\
\text { Population }\end{array}$ & (4) \\
\hline Dolecek et al, 2012 & Glioblastoma & $9440-9442$ & $\begin{array}{l}2000 \text { U.S. Standard } \\
\text { Population }\end{array}$ & $(5)$ \\
\hline Gittleman et al, 2015 & Glioblastoma & $9440-9442$ & $\begin{array}{l}2000 \text { U.S. Standard } \\
\text { Population }\end{array}$ & $(10)$ \\
\hline Dobec-Meić et al, 2006 & Glioblastoma & $N A$ & $\begin{array}{l}2001 \text { Census Data } \\
\text { (Croatia) }\end{array}$ & $(11)$ \\
\hline Gabriel et al, 2014 & Glioblastoma & $N A$ & $N A$ & $(12)$ \\
\hline \multirow[t]{2}{*}{ Kohler et al, 2011} & Glioblastoma & $N A$ & $\begin{array}{l}2000 \text { U.S. Standard } \\
\text { Population }\end{array}$ & $(16)$ \\
\hline & Oligodendroglial tumors & & & \\
\hline Ostrom et al, 2013 & Anaplastic oligodendroglioma & 9451,9460 & $\begin{array}{l}2000 \text { U.S. Standard } \\
\text { Population }\end{array}$ & (4) \\
\hline Dolecek et al, 2012 & Anaplastic oligodendroglioma & 9451,9460 & $\begin{array}{l}2000 \text { U.S. Standard } \\
\text { Population }\end{array}$ & $(5)$ \\
\hline \multirow[t]{2}{*}{ Dobec-Meić et al, 2006} & Anaplastic oligodendroglioma & $N A$ & $\begin{array}{l}2001 \text { Census Data } \\
\text { (Croatia) }\end{array}$ & (11) \\
\hline & Embryonal tumors & & & \\
\hline Ostrom et al, 2013 & Embryonal tumors, NOS & $\begin{array}{l}8963,9364,9470,9471, \\
9472,9473,9474,9480, \\
9490,9500,9501,9502,9508\end{array}$ & $\begin{array}{l}2000 \text { U.S. Standard } \\
\text { Population }\end{array}$ & (4) \\
\hline Dolecek et al, 2012 & Embryonal tumors, NOS & $\begin{array}{l}8963,9364,9470,9471, \\
9472,9473,9474,9490,9500, \\
9501,9502,9508\end{array}$ & $\begin{array}{l}2000 \text { U.S. Standard } \\
\text { Population }\end{array}$ & $(5)$ \\
\hline Smoll et al, 2012 & Medulloblastoma PNET & $9470,9471,9472,9474,9473$ & $\begin{array}{l}2000 \text { U.S. Standard } \\
\text { Population }\end{array}$ & $(15)$ \\
\hline \multirow[t]{2}{*}{ Kohler et al, 2011} & Embryonal tumors, NOS & $N A$ & $\begin{array}{l}2000 \text { U.S. Standard } \\
\text { Population }\end{array}$ & $(16)$ \\
\hline & Meningeal tumors & & & \\
\hline Gabriel et al, 2014 & Malignant meningioma & $N A$ & $N A$ & (12) \\
\hline
\end{tabular}

NA, information not available; ICD-O, International classification of diseases of oncology; PNET, primitive neuroectodermal tumor; NOS, not otherwise specified; U.S., United States.

may reflect incidence trends from a limited quantity of population material.
The time trend analysis was based on results from a number of studies, however the validity of the individual studies, 
including numbers of patients included and type of standard population, was not examined. Therefore, studies with reduced validity may have influenced the results of the current study as much as studies with high validity.

The data in the majority of studies that were evaluated in the current review were from the Central Brain Tumor Registry of the United States (CBTRUS), which use data from the SEER and National Program of Cancer Registry programs in the United States. Ostrom et al (4) identified that the data in these registries are reported according to United States law and may be considered as representative of the United States population. As the registries are regularly revised in terms of data collection, case definition and rate calculation, they may differ between editions and therefore the interpretation of comparisons with previous CBTRUS reports in the present review must be made with caution (4).

Gabriel et al (12) analyzed the incidence trends per 100,000 individuals in the African-American population of the United States. The results only included the six most prevalent types of primary brain tumor in their analysis, including anaplastic astrocytoma, glioblastoma multiforme, malignant meningioma, lymphoma, astrocytoma not otherwise specified (NOS) and glioma NOS. Gabriel et al (12) exclusively included the cases that were diagnosed as malignant, thus excluding lymphoma, astrocytoma NOS and glioma NOS. As the results excluded other types of malignant primary brain tumors, it is possible that relevant incidence data may have been excluded. As the incidence trend calculations were not age-adjusted this also reduces the validity of any comparison with other previous studies. Gabriel et al (12) was the only study that had analyzed the incidence trends of malignant meningiomas. However, as the cases were limited to the African-American population, this may not be representative of the incidence rate among the general population reducing the validity of these results.

The interpretation of the results from the present review may also be problematic as similar tumor groupings, including primary nerve sheath tumors and NOS, had differing ICD-O histology codes between the included studies. This may suggest that comparisons within the tumor groupings must be made with caution. A number of the included previous studies did not present the ICD-O histology codes of the cases. The number of inclusions and therefore the statistical power of the distinct incidence rates between male and female patients were varied across the studies. As the general incidence rate of high-grade brain tumors in male and female patients differs through time, a possible covariate may be that distinct tumor groupings are not analyzed in the same time period. This may result in an alteration in the incidence rate within high-grade tumors over time.

In conclusion, the present review indicates that there is no significant difference in the incidence rate between male and female patients with high-grade brain tumors and that there was no significant difference in the incidence rate trend between 1996-2004 and 2005-2010 in male or female patients ( $\mathrm{P}=0.101$ and $\mathrm{P}=0.472$, respectively). The present results must be interpreted with caution and further studies are required to fully elucidate this topic.

\section{References}

1. Practice B: Overview of brain tumours. http://bestpractice.bmj. com/best-practice/monograph/262.html.

2. Louis DN, Ohgaki H, Wiestler OD, Cavenee WK, Burger PC, Jouvet A, Scheithauer BW and Kleihues P: The 2007 WHO classification of tumours of the central nervous system. Acta Neuropathol 114: 97-109, 2007.

3. Asklund T, Malmström A, Bergqvist M, Björ O and Henriksson R: Brain tumors in Sweden: Data from a population-based registry 1999-2012. Acta Oncol 54: 377-384, 2015.

4. Ostrom QT, Gittleman H, Farah P, Ondracek A, Chen Y, Wolinsky Y, Stroup NE, Kruchko C and Barnholtz-Sloan JS: CBTRUS statistical report: Primary brain and central nervous system tumors diagnosed in the United States in 2006-2010. Neuro Oncol 15 (Suppl 2): ii1-ii56, 2013.

5. Dolecek TA, Propp JM, Stroup NE and Kruchko C: CBTRUS statistical report: Primary brain and central nervous system tumors diagnosed in the United States in 2005-2009. Neuro Oncol 14 (Suppl 5): v1-v49, 2012.

6. Deltour I, Johansen C, Auvinen A, Feychting M, Klaeboe L and Schüz J: Time trends in brain tumor incidence rates in Denmark, Finland, Norway, and Sweden, 1974-2003. J Natl Cancer Inst 101: 1721-1724, 2009.

7. Center for Disease Control and Prevention: National program of cancer registries (NPCR). https://www.cdc.gov/cancer/npcr/.

8. National Program of Cancer Registries, and Surveillance, Epidemiology and End Results Program (SEER): SEER Registries. https://seer.cancer.gov/.

9. Kleihues P, Burger PC and Scheithauer BW: The new WHO classification of brain tumours. Brain Pathol 3: 255-268, 1993.

10. Gittleman HR, Ostrom QT, Rouse CD, Dowling JA, de Blank PM, Kruchko CA, Elder JB, Rosenfeld SS, Selman WR, Sloan AE and Barnholtz-Sloan JS: Trends in central nervous system tumor incidence relative to other common cancers in adults, adolescents, and children in the United States, Cancer 121: 102-112, 2015.

11. Dobec-Meić B, Pikija S, Cvetko D, Trkulja V, Pazanin L, Kudelić N, Rotim K, Pavlicek I and Kostanjevec AR: Intracranial tumors in adult population of the Varazdin County (Croatia) 1996-2004: A population-based retrospective incidence study. J Neurooncol 78: 303-310, 2006.

12. Gabriel A, Batey J, Capogreco J, Kimball D, Walters A, Tubbs RS and Loukas M: Adult brain cancer in the U.S. black population: A Surveillance, Epidemiology, and End Results (SEER) analysis of incidence, survival, and trends. Med Sci Monit 20: 1510-1517, 2014.

13. Smoll NR and Hamilton B: Incidence and relative survival of anaplastic astrocytomas. Neuro Oncol 16: 1400-1407, 2014.

14. International Agency for Research on Cancer: International Classification of Diseases for Oncology. http://codes.iarc.fr/.

15. Smoll NR and Drummond KJ: The incidence of medulloblastomas and primitive neurectodermal tumours in adults and children. J Clin Neurosci 19: 1541-1544, 2012.

16. Kohler BA, Ward E, McCarthy BJ, Schymura MJ, Ries LA, Eheman C, Jemal A, Anderson RN, Ajani UA and Edwards BK: Annual report to the nation on the status of cancer, 1975-2007, featuring tumors of the brain and other nervous system. J Natl Cancer Inst 103: 714-736, 2011. 